\title{
In vivo assessment of antihyperglycemic and antioxidant activity from oil of linseed in streptozotocin induced diabetic rats
}

\author{
Manoj Kumar ${ }^{1}$, Sunil Sharma ${ }^{2 \star}$ and Neeru Vasudeva ${ }^{2}$ \\ ${ }^{1}$ Department of Pharmaceutical Sciences, Guru Jambheshwar University of Science and Technology, Hisar, Haryana- \\ 125001, India. \\ ${ }^{2}$ Pharmacology Divisions, Department of Pharmaceutical Sciences, Guru Jambheshwar University of Science and \\ Technology, Post Box: 38, Hisar-125001, India.
}

Accepted 27 May, 2013

\begin{abstract}
In the present study, the antihyperglycemic and antioxidant effects of oil from seeds of Linum usitatissimum Linn. (LO) were investigated. A streptozotocin-nicotinamide (STZ) rat model of hyperglycaemia was used to evaluate the antihyperglycemic and antioxidant properties of oil of linseed. The body weight, oral glucose tolerance test and biochemical parameters namely; glucose level, insulin level, liver glycogen content, glycosylated hemoglobin and antioxidant parameters were estimated for all treated groups and compared against diabetic control group. LO (500 and $1000 \mathrm{mg} / \mathrm{kg} / \mathrm{day}$ ) in respective groups of diabetic animals administered for 28 days reduced the blood glucose level in streptozotocin-nicotinamide induced diabetic rats. There was significant increase in body weight, liver glycogen content, plasma insulin level and decrease in the blood glucose and glycosylated hemoglobin in test groups as compared to control group. In vivo antioxidant studies on STZ-nicotinamide induced diabetic rats revealed decreased malondialdehyde (MDA) and increased reduced glutathione (GSH). The findings demonstrate that LO have excellent antihyperglycemic and antioxidant activities and thus have great potential as a source for natural health products.
\end{abstract}

Key words: Streptozotocin, Linum usitatissimum, fixed oil, malondialdehyde (MDA), diabetes.

\section{INTRODUCTION}

A number of plants are being used from ancient times for the management of various disease like diabetes, hyperlipidemia, cancer, inflammation, pain etc. Many herbal products including several metals and minerals have been described for the care of diabetes mellitus in ancient literature (Nadkarni et al., 1992). Ayurveda, an ancient Indian form of medicine, deals with plants and plant extracts. This indigenous form of medicine uses the active ingredients present in plants for treating diseases
(Lewis and Elvin-Lewis, 1997). Plant drugs are frequently considered to be less toxic and free from side effects than synthetic ones (Momin, 1987). Many herbs have shown to possess hypoglycaemic action in animals and humans (Twaij and Al-Badr, 1988; Gupta, 1994).

Linum usitatissimum Linn. (Linaceae) is one of the important medicinal plants being used in various systems of medicine and food (Velisek et al., 1995). Human being has consumed flaxseed since the beginning of the 
earliest civilizations. It was used traditionally to relieve abdominal pains and also as energy source from ancient time. Flax is considered a source of food as it contains alpha-linolenic acid lignans and polysaccharides (other than starch), all of which have positive effects in disease prevention (Rubilar et al., 2010).

Diabetes mellitus is a metabolic disorder which causes great morbidity in developed and developing countries. Diabetes was known to ancient Indian physicians as 'madumeha'. The metabolism of carbohydrates, fats and proteins are malformed in diabetes and patients with this disorder are at an increased risk of various complications like coronary heart disease, peripheral vascular disease and cerebrovascular disease (Brown, 1994; Stamler et al., 1993). It is associated with profound alterations in the plasma lipid and lipoprotein profile thereby an increased risk of premature atherosclerosis, coronary insufficiency and myocardial infarction exists (Betteridge, 1997). Accumulation of lipids in diabetes is mediated through a variety of regulatory processes, especially insulin deficiency, thereby rendering the diabetic patient more prone to hypercholesterolemia and hypertriglyceridemia [Jaiprakash et al., 1993].

The LO has been widely used in the food industries from centuries. As far as we know, the effect of LO on the blood profiles in diabetic models has not been studied. In light of these findings, we carried out this study for the evaluation of antihyperglycemic, and antioxidant potential of LO.

\section{MATERIALS AND METHODS}

\section{Drugs and chemicals}

The drugs and chemicals used in the study were glibenclamide (Torrent Pharmaceutical, Ahmadabad), streptozotocin, heparin (SRL, India), EDTA (Hi-media Lab. Pvt Ltd., Mumbai, India), Ellman's reagent (5,5'-dithiobis-(2-nitro-benzoic acid); DTNB), sodium sulphate, methanol, pyridine, anthrone, thiourea, benzoic acid, sodium chloride (SD Fine Chem Ltd., Mumbai, India). All the chemicals used in the study were of analytical grade.

\section{Isolation of oil}

The dried seeds of linseed were purchased from Chaudhary Charan Singh Haryana Agriculture University, Hisar, India. The seeds were crushed and oil was extracted by hot compression method. The percentage yield of oil was found to be $35 \% \mathrm{w} / \mathrm{w}$.

\section{Experimental animals}

Healthy albino wistar rats (150 to $250 \mathrm{~g}$ ) were procured from Disease Free Small Animal House, Lala Lajpat Rai University of Veterinary and Animal Sciences, Hisar (Haryana). The rats were housed in (Polycarbonate cage size: $29 \times 22 \times 14 \mathrm{~cm}$ ) under laboratory standard conditions $\left(25 \pm 3^{\circ} \mathrm{C}\right.$ : 35 to $60 \%$ humidity) with alternating light and dark cycle of $12 \mathrm{~h}$ each and were fed with a standard rat pellet diet (Hindustan Lever Ltd, Mumbai, India) and water ad libitum. The experimental protocol was approved by Institutional Animals Ethics Committee (IAEC) and Animal care was taken as per the guidelines of Committee for the Purpose of Control and Supervision of Experiments on Animals (CPCSEA), Govt. of India (Registration No. 0436).

\section{Induction of diabetes}

Type II diabetes mellitus (NIDDM) was induced in overnight fasted animals by a single intraperitoneal injection of $50 \mathrm{mg} / \mathrm{kg} \mathrm{STZ}$ in 0.1 $M$ citrate buffer ( $\mathrm{pH}-4.5)$ in a volume of $1 \mathrm{ml} / \mathrm{kg}$ body weight $15 \mathrm{~min}$ after the i.p. administration of $110 \mathrm{mg} / \mathrm{kg}$ nicotinamide. Diabetes was developed and stabilized over a period of 7 days. Diabetes was confirmed by the elevated blood glucose levels determined at $72 \mathrm{~h}$ and on 7th day after injection. Only rats confirmed with permanent NIDDM (glucose level above $250 \mathrm{mg} / \mathrm{dl}$ ) were used in the study. All the animals were allowed free access to tap water and pellet diet and maintained at room temperature in plastic cages as per the guidelines of Institute of Animal Ethics committee. Blood was collected by intraocular route (Kumar et al., 2012).

\section{Experimental design}

Rats were divided into the following groups comprising six rats in each group after the induction and confirmation of diabetes.

\section{For acute antihyperglycemic model}

In the acute antihyperglycemic models, the study was carried out for $4 \mathrm{~h}$ to check if the plant possess some antidiadbetic effect.

Group 1: Normal rats.

Group 2: Diabetic control.

Group 3: Diabetic animals were administered glibenclamide $(0.6 \mathrm{mg} / \mathrm{kg}$ p.o).

Group 4: Diabetic animal were administered orally $500 \mathrm{mg} / \mathrm{kg} /$ day of LO.

Group 5: Diabetic animal were administered orally $1000 \mathrm{mg} / \mathrm{kg} /$ day of LO.

\section{For chronic antihyperglycemic model}

In the chronic antihyperglycemic models, the animal were treated with different doses that is, 500 and $1000 \mathrm{mg} / \mathrm{kg}$ for 28 days to study the various parameters of the diabetes to confirm the antihyperglycemic activity of LO in streptozotocin induced diabetes in rats.

Group 1: Normal rats.

Group 2: Diabetic control.

Group 3: Diabetic animals were administered glibenclamide $(0.6 \mathrm{mg} / \mathrm{kg}$ p.o).

Group 4: Diabetic animal were administered orally $500 \mathrm{mg} / \mathrm{kg} /$ day of LO.

Group 5: Diabetic animal were administered orally $1000 \mathrm{mg} / \mathrm{kg} /$ day of LO.

\section{Sample collection}

\section{Blood sample}

In acute model, the blood was collected from retrorbital vein of the 
rats previously fasted for $24 \mathrm{~h}$. In chronic model, the $24 \mathrm{~h}$ fasted animals were sacrificed by cervical decapitation on 28th day of treatment. Trunk blood was collected in heparinized tubes. Plasma was obtained by centrifugation at $5000 \mathrm{rpm}$ for $5 \mathrm{~min}$ to determine the biochemical parameters; glucose, insulin, cholesterol etc.

\section{Estimation of plasma glucose and cholesterol}

Plasma cholesterol and glucose level were measured by commercial supplied biological kit Erba Glucose Kit (GOD-POD Method) and Erba Cholesterol Kit (CHOD-PAP Method), respectively using Chem 5 Plus- $V_{2}$ Auto-analyser (Erba Mannhein Germany) in plasma sample. Glucose and cholesterol values were calculated as $\mathrm{mg} / \mathrm{dl}$ blood sample.

\section{Estimation of glycosylated hemoglobin (Hb1Ac)}

Glycosylated hemoglobin was measured using commercial supplied biological kit (Erba Diagnostic) in plasma sample using Chem 5 Plus- $V_{2}$ Auto-analyser (Erba Mannhein Germany). Values are expressed as the percent of total hemoglobin.

\section{Estimation of insulin}

Serum insulin level was measured by an enzyme-linked immunosorbent assay (ELISA) procedure using Mercodia rat insulin ELISA kit. Briefly, the solid phase two-site enzyme immunoassay is based on the direct sandwich technique in which two monoclonal antibodies are directed against separate antigenic determinants 35 (epitopes) on the insulin molecule. During incubation, insulin in the sample reacts with peroxidase-conjugated anti-insulin antibodies and anti-insulin antibodies bound to the micro titration well. After washing three times, unbound enzyme labeled antibody was removed. The bound conjugated insulin was detected by reacting with 3, 3', 5, 5'-tetramethylbenzidine. The reaction was stopped by adding acid to give a colorimetric end-point, and optical density was measured with a micro plate auto reader (Bio-tek Instrument Inc., USA) at a wavelength of $450 \mathrm{~nm}$. The serum insulin is expressed as $\mu g / l$.

\section{Estimation of liver glycogen content}

Liver glycogen estimation was done by the method as described by Seifter et al. (1950) with some modifications (Seifter et al., 1950). Immediately after excision from the animal, $1 \mathrm{~g}$ of the liver was dropped into a previously weighed test tube containing $3 \mathrm{ml}$ of $30 \%$ potassium hydroxide solution. The weight of the liver sample was determined. The tissue was then digested by heating the tube for 20 minutes in boiling water bath. The digest was then cooled, transferred quantitatively to a $50 \mathrm{ml}$ volumetric flask, and diluted to the mark with water. The contents of the flask were then thoroughly mixed and a measured portion was then further diluted with water in a second volumetric flask so as to yield a solution of glycogen (3 to $30 \mu \mathrm{g} / \mathrm{ml}$ ). Five $\mathrm{ml}$ aliquots of the final dilution were then pipetted into Evelyn tube and the determination with anthrone was carried out. The amount of glycogen in the aliquot used was then calculated using the following equation:

$\mu \mathrm{g}$ of glycogen in aliquot $=100 \mathrm{U} / 1.11 \mathrm{~S}$

$\mathrm{U}$ is the optical density of unknown solution. $\mathrm{S}$ is the optical density of the $100 \mu \mathrm{g}$ glucose and 1.11 is the factor determined by Morris in
1948 for the conversion of the glucose to the glycogen (Seifter et al., 1950).

\section{In vivo antioxidant activity}

\section{Estimation of MDA level}

Malondialdehyde (MDA), an index of free radical generation/lipid peroxidation, was determined as described by Okhawa et al. (1979) with some modification (Okhawa et al., 1979). Briefly, the reaction mixture consisted of $0.2 \mathrm{ml}$ of $8.1 \%$ sodium lauryl sulphate, $1.5 \mathrm{ml}$ of $20 \%$ acetic acid $(\mathrm{pH} 3.5)$ and $1.5 \mathrm{ml}$ of $0.8 \%$ aqueous solution of thiobarbituric acid added to $0.2 \mathrm{ml}$ of blood plasma. The mixture was made up to $4.0 \mathrm{ml}$ with distilled water and heated at $95^{\circ} \mathrm{C}$ for 60 min. After cooling the contents under running tap water, $5.0 \mathrm{ml}$ of $n$-butanol and pyridine $(15: 1 \mathrm{v} / \mathrm{v})$ and $1.0 \mathrm{ml}$ of distilled water was added. The contents were centrifuged at about 3,000 rpm for 10 min. The organic layer was separated out and its absorbance was measured at $532 \mathrm{~nm}$ using double beam UV-Visible spectrophotometer (Systronics 2203, Bangalore, India) against a blank. MDA values were calculated using the extinction coefficient of MDAthiobarbituric acid complex $1.56 \times 10^{5} \mathrm{l} / \mathrm{mol} \mathrm{cm}$ and expressed as $\mathrm{nmol} / \mathrm{ml}$.

\section{Estimation of reduced glutathione level}

The tissue sample (liver $200 \mathrm{mg}$ ) was homogenized in $8.0 \mathrm{ml}$ of $0.02 \mathrm{M}$ EDTA in an ice bath. The homogenates were kept in the ice bath until used. Aliquots of $5.0 \mathrm{ml}$ of the homogenates were mixed in $15.0 \mathrm{ml}$ test tubes with $4.0 \mathrm{ml}$ distilled water and $1.0 \mathrm{ml}$ of $50 \%$ trichloroacetic acid (TCA). The tubes were centrifuged for $15 \mathrm{~min}$ at approximately $3,000 \mathrm{rpm}, 2.0 \mathrm{ml}$ of supernatant was mixed with 4.0 $\mathrm{ml}$ of $0.4 \mathrm{M}$ Tris buffer $\mathrm{pH} 8.9,0.1 \mathrm{ml}$ Ellman's reagent [5,5dithiobis-(2-nitro-benzoic acid)] (DTNB) added and the sample shaken. The absorbance was read within $5 \mathrm{~min}$ of the addition of DTNB at $412 \mathrm{~nm}$ against a reagent blank with no homogenate. Results are expressed as $\mu \mathrm{mol} \mathrm{GSH} / \mathrm{g}$ tissue.

\section{Statistical analysis}

The data for various biochemical parameters were evaluated by use of one-way analysis of variance (ANOVA), followed by Dunnett's t-test using the software Sigma-Stat 3. In all the tests, the criterion for statistical significance was $p<0.05$.

\section{RESULTS}

\section{Oral glucose tolerance test}

The effect of LO on plasma glucose level after glucose loading of $2 \mathrm{~g} / \mathrm{kg}$ body weight orally to the STZ diabetic rats is expressed in the Table 1. The blood glucose level rises to a maximum in $60 \mathrm{~min}$ after glucose loading. The oil $(500 \mathrm{mg} / \mathrm{kg} /$ day and $1000 \mathrm{mg} / \mathrm{kg} /$ day body weight) treated groups showed a significant decrease $(p<0.01)$ in level of glucose as compared to control group. The oil treated group showed a marked fall in glucose level in 90 to 120 min interval. 
Table 1. Effect of Linum usitatissimum oil in oral glucose tolerance test (OGTT).

\begin{tabular}{|c|c|c|c|c|c|c|}
\hline \multirow{2}{*}{ Treatment } & \multirow{2}{*}{ Dose $(\mathrm{mg} / \mathrm{kg})$} & \multicolumn{5}{|c|}{ Mean blood glucose concentration $(\mathrm{mg} / \mathrm{dl}) \pm$ SEM } \\
\hline & & $0 \mathrm{~min}$ & $30 \mathrm{~min}$ & $60 \mathrm{~min}$ & $90 \mathrm{~min}$ & 120 min \\
\hline Normal & - & $80 \pm 2.6$ & $87 \pm 2.8$ & $90 \pm 3.8$ & $86 \pm 2.5$ & $83 \pm 2.7$ \\
\hline Diabetic control & - & $290 \pm 4.6$ & $390 \pm 5.3$ & $413.2 \pm 4.3$ & $360 \pm 2.7$ & $331 \pm 2.8$ \\
\hline LUO & 500 & $320 \pm 2.9$ & $332 \pm 2.7$ & $350 \pm 3.0$ & $317 \pm 3.6^{*}$ & $288 \pm 4.1^{\star *}$ \\
\hline LUO & 1000 & $372 \pm 3.6$ & $383 \pm 4.5$ & $401 \pm 4.1$ & $360 \pm 3.4^{* *}$ & $301 \pm 3.3^{* *}$ \\
\hline
\end{tabular}

Values are presented as mean \pm SEM.; $n=6$ in each group. One way ANOVA followed by Dunnett's test ${ }^{* *} \mathrm{p}<0.01$ versus diabetic control; LUO: Linum usitatissimum oil

Table 2. Effect of Linum usitatissimum oil in STZ induced diabetic rats in acute antihyperglycemic study.

\begin{tabular}{|c|c|c|c|c|c|c|}
\hline \multirow{2}{*}{ Treatment } & \multirow{2}{*}{ Dose (mg/kg p.o) } & \multicolumn{5}{|c|}{ Mean blood glucose concentration (mg/dl) \pm SEM } \\
\hline & & $\mathbf{O h}$ & $1 / 2 h$ & $1 \mathrm{~h}$ & $2 \mathrm{~h}$ & $4 \mathrm{~h}$ \\
\hline Normal & - & $76 \pm 4.2$ & $80 \pm 3.2$ & $77 \pm 2.5$ & $82 \pm 4.1$ & $79 \pm 5.3$ \\
\hline Control & - & $340.5 \pm 10.2$ & $342 \pm 11.3$ & $346 \pm 7.6$ & $341.0 \pm 6.7$ & $332.0 \pm 7.2$ \\
\hline LUO & 500 & $350 \pm 5.7$ & $340.1 \pm 5.4$ & $310 \pm 4.5^{\star *}$ & $305 \pm 3.4^{* *}$ & $288 \pm 3.6^{* *}$ \\
\hline LUO & 1000 & $338 \pm 1.8$ & $314 \pm 1.9^{*}$ & $296 \pm 2.3^{\star *}$ & $277 \pm 2.4^{\star *}$ & $262 \pm 4.9^{* *}$ \\
\hline Glibenclamide & 0.6 & $348 \pm 7.1$ & $328 \pm 3.2^{* *}$ & $288 \pm 6.4^{\star *}$ & $260 \pm 5.2^{\star *}$ & $249.0 \pm 6.8^{* *}$ \\
\hline
\end{tabular}

Values are presented as mean \pm SEM; $n=6$ in each group. One way ANOVA followed by Dunnett's test ${ }^{*} p<0.05 ;{ }^{* *} p$ $<0.01$ versus diabetic control; LUO: Linum usitatissimum oil.

Table 3. Effect of Linum usitatissimum oil in STZ induced diabetic rats in chronic antihyperglycemic study.

\begin{tabular}{lcccccc}
\hline \multirow{2}{*}{ Treatment } & \multirow{2}{*}{ Dose (mg/kg p.o) } & \multicolumn{5}{c}{ Mean blood glucose concentration $(\mathbf{m g} / \mathbf{d l}) \pm \mathbf{S E M}$} \\
\cline { 2 - 7 } & $\mathbf{0}^{\text {th }}$ Day & $\mathbf{7}^{\text {th }}$ Day & $\mathbf{1 4}^{\text {th }}$ Day & $\mathbf{2 1}^{\text {st }}$ Day & $\mathbf{2 8}^{\text {th }}$ \\
\hline Normal & - & $80 \pm 4.2$ & $79 \pm 3.2$ & $82 \pm 2.5$ & $85.5 \pm 4.1$ & $78 \pm 2.1$ \\
Control & - & $380 \pm 7.3$ & $379 \pm 7.6$ & $384 \pm 6.7$ & $416 \pm 7.2$ & $410 \pm 5.4$ \\
LUO & 500 & $345 \pm 7.4$ & $299 \pm 4.5^{* *}$ & $278 \pm 5.2^{* *}$ & $245 \pm 6.1^{* *}$ & $170 \pm 6.2^{* *}$ \\
LUO & 1000 & $370 \pm 5.2$ & $286 \pm 5.9^{* *}$ & $210 \pm 5.8^{* *}$ & $190 \pm 4.4^{* *}$ & $155 \pm 5.8^{* *}$ \\
Glibenclamide & 0.6 & $344 \pm 8.4$ & $259.2 \pm 7.7^{* *}$ & $166.3 \pm 4.9^{* *}$ & $140 \pm 2.6^{* *}$ & $124 \pm 1.8^{* *}$ \\
\hline
\end{tabular}

Values are presented as mean $\pm S E M ; n=6$ in each group. One way ANOVA followed by Dunnett's test ${ }^{* *} p<0.01$ versus diabetic control; LUO: Linum usitatissimum oil

\section{Effect of LO on STZ diabetic rats in acute study}

Administration of $\mathrm{LO}$ at a dose $500 \mathrm{mg} / \mathrm{kg} /$ day body weight p.o. to STZ diabetic rats showed reduction in blood glucose level from 350 to $288 \mathrm{mg} / \mathrm{dl}$ at 4 th $\mathrm{h}$. When the dose was increased as $1000 \mathrm{mg} / \mathrm{kg} /$ day then the blood glucose level decreased from 338 to $262 \mathrm{mg} / \mathrm{dl}$ which was found significant $(p<0.01)$ when compared with diabetic control (Table 2).

\section{Effect of LO on STZ diabetic rats in chronic study}

In chronic study, administration of LO at the dose of 500 $\mathrm{mg} / \mathrm{kg}$ body weight to STZ diabetic rats for 28 days showed a fall in plasma glucose level from 345 to 170 $\mathrm{mg} / \mathrm{dl}$ on 28th day when compared to 0 day value. LO at the dose of $1000 \mathrm{mg} / \mathrm{kg} /$ day body weight showed a significant $(p<0.01)$ fall in plasma glucose level from 370 to $155 \mathrm{mg} / \mathrm{dl}$ on 28th day (Table 3 ).

\section{Effect of LO on body weight}

An increase in the body weight of normal rats was observed whereas the weight of diabetic control rats decreased from day 1 to day 28. LO at the dose of 500 and $1000 \mathrm{mg} / \mathrm{kg} / \mathrm{day}$ body weight when administered to respective groups of diabetic rats showed a significant increase in body weight as compared to the diabetic 
control group $(p<0.01)$ (Table 4).

\section{Effect of LO on insulin level}

Table 5 shows the level of plasma insulin in the control and experimental groups of rats. Diabetic rats showed a significant decrease $(p<0.01)$ in plasma insulin compared with normal rats. Oral administration of LO at the dose of $500 \mathrm{mg} / \mathrm{kg} /$ day and $1000 \mathrm{mg} / \mathrm{kg} /$ day body weight respectively showed a significant increase in plasma insulin level in respective groups as compared to control rats.

\section{Effect of LO on glycosylated hemoglobin (HbA1c)}

The effect of LO on HbA1c in STZ diabetic rats is shown in the Table 5. The level of glycosylated hemoglobin significantly increased $(p<0.01)$ in diabetic rats as compared to normal control group. The diabetic rats when treated with LO for 28 days showed a significant $(p<$ 0.01 ) decrease in level of glycosylated $\mathrm{Hb}$ as compared to untreated diabetic group. The fall in glycosylated hemoglobin level was found to be dose dependent (Table $5)$.

\section{Effect of LO on hepatic glycogen}

The hepatic glycogen content in diabetic rats decreased sharply as compared to control animal (Table 5). Chronic administration of LO at both the doses to diabetic rats, a significant increase $(p<0.01)$ in liver glycogen content, was observed as compared to diabetic control group.

\section{Effect of LO on lipid profile}

Table 6 shows the level of lipids in normal and tested animals. There was a significant decrease $(p<0.01)$ in the level of HDL-cholesterol and a significant increase in the levels of total cholesterol and triglycerides in diabetic rats when compared to normal rats. The administration of LO reversed the level of lipids significantly $(p<0.05$ and $\mathrm{p}<0.01)$.

\section{Effect of LO on in vivo antioxidant parameters}

The data depicted in Table 7 shows the effect of LO on plasma malonaldehyde and reduced glutathione level. Plasma MDA level was found to be significantly higher in STZ diabetic rats compared to normal rats. The LO at dose $1000 \mathrm{mg} / \mathrm{kg}$ body weight p.o significantly reduced $(p<0.01)$ the level of MDA in diabetic rats. Plasma GSH level was found to be significantly lowered at both the doses of LO in STZ diabetic rats as compared to normal rats. The chronic administration of LO at $1000 \mathrm{mg} / \mathrm{kg}$ body weight significantly increased the level of glutathione in diabetic rats.

\section{DISCUSSION}

The aim of the study was to evaluate the antidiabetic and antioxidant potential of the LO in STZ induced diabetic rats. Diabetes mellitus causes a disturbance in the uptake of glucose as well as glucose metabolism. A dose of STZ as low as $50 \mathrm{mg} / \mathrm{kg}$ produces an incomplete destruction of pancreatic beta cells even though the rats become permanently diabetic (Kumar et al., 2012). After treatment with a low dose of STZ, many beta cells survive and regeneration is also possible (Kumar et al., 2012). Hyperglycemia generates a high level of free radicals by autoxidation of glucose and protein glycation, and oxidative stress has been reported to be a positive factor of cardiovascular complications in STZ-induced diabetes mellitus (Okutan et al., 2005). Hyperglycemia is associated with the generation of reactive oxygen species (ROS), causing oxidative damage particularly to heart, kidney, eyes, nerves, liver, small and large vessels and gastrointestinal system (Tunali and Yanardag, 2006). The increased levels of plasma glucose in STZ-induced diabetic rats were lowered by LO administration. The plasma glucose lowering activity of LO was comparable to glibenclamide, a standard hypoglycemic drug that stimulates insulin secretion from pancreatic beta cells (Tian et al., 1998). From the results of the present study, it appears that still insulin producing cells are functioning and the stimulation of insulin release could be responsible for most of the metabolic effects. It may be suggested that the mechanism of action of LO is similar to glibenclamide. The glucose lowering activity of LO may be related to both pancreatic (enhancement of insulin secretion) and extra pancreatic (peripheral utilization of glucose) mechanism.

An increase in the level of glycosylated hemoglobin (HbA1c) in the diabetic control group of rats is due to the presence of large amount of blood glucose which reacts with hemoglobin to form glycosylated hemoglobin (Chattopadhyay, 1999). Oxidative stress increases due to the activation of transcription factors, advanced glycated end products (AGEs), and protein kinase $\mathrm{C}$. If diabetes is persistent for a long time, the glycosylated hemoglobin is found to increase (Sheela and Augusti, 1992). The level of $\mathrm{HbA}_{1} \mathrm{C}$ was decreased after the administration of $\mathrm{LO}$ $1000 \mathrm{mg} / \mathrm{kg}$ as compared to diabetic control group $\left({ }^{* *} \mathrm{p}<\right.$ $0.01)$.

In STZ induced diabetes mellitus, the loss of body weight is caused by increase in muscle wasting and catabolism of fat and proteins (Chakravarti et al., 1981). Due to insulin deficiency, protein content is decreased in 
Table 4. Effect of Linum usitatissimum oil on body weight in diabetic rats.

\begin{tabular}{clcccc}
\hline S/No. & Treatment & Dose (mg/kg p.o) & $\begin{array}{c}\text { Initial body } \\
\text { weight } \mathbf{( g )}\end{array}$ & $\begin{array}{c}\text { Final body } \\
\text { weight } \mathbf{( g )}\end{array}$ & Change in weight \\
\hline 1 & Normal & - & $220 \pm 1.1$ & $240 \pm 1.5$ & +20 \\
2 & Diabetic control & - & $215 \pm 1.8$ & $194 \pm 2.0$ & $-21^{\text {a }}$ \\
3 & LUO & 500 & $250 \pm 2.2$ & $255 \pm 1.0$ & +5 \\
4 & LUO & 1000 & $245 \pm 1.3$ & $255 \pm 1.4$ & $+10^{\star \star}$ \\
5 & Glibenclamide & 0.6 & $220 \pm 4.7$ & $250 \pm 1.8$ & $+30^{\star *}$ \\
\hline
\end{tabular}

Values are presented as mean \pm SEM; $n=6$ in each group. One way ANOVA followed by Dunnett's test ${ }^{a} p<0.01$ versus normal; ${ }^{* *} p<0.01$ versus diabetic control; LUO: Linum usitatissimum oil.

Table 5. Effect of Linum usitatissimum oil on glycosylated hemoglobin ( $\mathrm{HbA} 1 \mathrm{c})$, hepatic glycogen and insulin in the study.

\begin{tabular}{lcccc}
\hline Treatment & Dose $(\mathbf{m g} / \mathbf{k g})$ & HbA1c $(\%$ of $\mathbf{~ b})$ & Hepatic glycogen $(\mathbf{m g} / \mathbf{g}$ wt of tissue) & Insulin (micro U/ml) \\
\hline Normal & - & $6 \pm 1.4$ & $74 \pm 6.6$ & $14 \pm 2.1$ \\
Diabetic control & - & $11.3 \pm 2.4^{\mathrm{a}}$ & $27 \pm 4.5^{\mathrm{a}}$ & $7.9 \pm 1.1^{\mathrm{a}}$ \\
LUO & 500 & $9.0 \pm 2.2$ & $47 \pm 1.8^{*}$ & $10 \pm 2.0$ \\
LUO & 1000 & $7.2 \pm 2.6^{\star *}$ & $64 \pm 3.6^{* \star}$ & $12 \pm 2.5^{\star}$ \\
Glibenclamide & 0.6 & $7.0 \pm 0.7^{\star *}$ & $66 \pm 2.8^{\star *}$ & $11.9 \pm 1.0^{*}$ \\
\hline
\end{tabular}

Values are presented as mean \pm SEM; $n=6$ in each group. One way ANOVA followed by Dunnett's test ${ }^{a} p<0.01$ versus normal; ${ }^{*} p<$ $0.05 ;{ }^{* *} p<0.01$ versus diabetic control; LUO: Linum usitatissimum oil.

Table 6. Effect of Linum usitatissimum oil on Lipid profile.

\begin{tabular}{lcccc}
\hline Treatment & Dose (mg/kg) & Cholesterol (mg/dl) & Triglyceride (mg/dl) & HDL (mg/dl) \\
\hline Normal & - & $85 \pm 1.5$ & $16 \pm 2.5$ & $66 \pm 1.9$ \\
Diabetic control & - & $232 \pm 2.4^{\mathrm{a}}$ & $43 \pm 3.1^{\mathrm{a}}$ & $37.4 \pm 1.2^{\mathrm{a}}$ \\
LUO & 500 & $177 \pm 3.6^{* *}$ & $29 \pm 1.6^{* *}$ & $44 \pm 2.1$ \\
LUO & 1000 & $111 \pm 2.5^{* *}$ & $21 \pm 1.3^{* *}$ & $48 \pm 1.3^{*}$ \\
Glibenclamide & 0.6 & $138 \pm 1.8^{* *}$ & $14.4 \pm 1.2^{* *}$ & $53 \pm 1.8^{*}$ \\
\hline
\end{tabular}

Values are presented as mean \pm SEM; $n=6$ in each group. One way ANOVA followed by Dunnett's test ${ }^{a} p<$ 0.01 versus normal; ${ }^{*} p<0.05 ;{ }^{* *} p<0.01$ versus diabetic control; LUO: Linum usitatissimum oil.

muscular tissue by proteolysis (Flat et al., 1990). A decrease in body weight was registered in case of STZ diabetic control group rats while in tested groups the weight loss was reversed. Fatty acid mobilisation from adipose tissue is sensitive to insulin. Insulin's most potent action is the suppression of adipose tissue lipolysis (Campbell et al., 1992). A rise in plasma insulin concentration of only $5 \mathrm{lU} / \mathrm{ml}$ inhibits lipolysis by $50 \%$, whereas a reduction in basal insulin levels result in a marked acceleration of lipolysis (Bonadonna et al., 1990). We demonstrated that LO increased plasma insulin concentrations in diabetic rats. Insulin levels higher than those of the control group may result in inhibition of lipolysis and decreased plasma triglyceride and cholesterol levels. Some studies suggest that the antihyperglycemic action of traditional antidiabetic plant extracts may be due in part to decreased glucose absorption in vivo (Gallagher et al., 2003). This mechanistic explanation may also apply to the actions of LO in lowering the triglyceride and cholesterol level.

The conversion of glucose to glycogen in the liver cells is dependent on the extracellular glucose concentration and on the availability of insulin which stimulates glycogen synthesis over a wide range of glucose concentration (Kumar et al., 2011). Diabetes reduces activity of glycogen synthase thereby affecting the glycogen storage and synthesis in rat liver and skeletal muscle (Kumar et al., 2011). Oral administration of LO $1000 \mathrm{mg} / \mathrm{kg}$ body weight significantly increased hepatic glycogen levels in STZ diabetic rats possibly because of the reactivation of the glycogen synthase system as a result of increased insulin secretion. 
Table 7. Effect of Linum usitatissimum oil on antioxidant parameters (MDA and GSH).

\begin{tabular}{lccc}
\hline Treatment & Dose $(\mathbf{m g} / \mathbf{k g})$ & MDA $(\mathbf{n m o l} / \mathbf{d l})$ & GSH $(\boldsymbol{\mu m o l} / \mathbf{g})$ \\
\hline Normal & - & $2.8 \pm 0.2$ & $41.2 \pm 2.8$ \\
Diabetic control & - & $5.4 \pm 0.4^{\mathrm{a}}$ & $14 \pm 1.15^{\mathrm{a}}$ \\
LUO & 500 & $3.8 \pm 0.7$ & $22 \pm 2.4$ \\
LUO & $1000 \mathrm{mg} / \mathrm{kg}$ & $3.1 \pm 0.3^{* *}$ & $34 \pm 2.1^{* *}$ \\
Glibenclamide & $0.6 \mathrm{mg} / \mathrm{kg}$ & $3.0 \pm 0.2^{* *}$ & $38 \pm 1.8^{* *}$ \\
\hline
\end{tabular}

Values are presented as mean \pm SEM; $n=6$ in each group. One way ANOVA followed by Dunnett's test ${ }^{a} p<0.01$ versus normal; ${ }^{* *} p<0.01$ versus diabetic control; LUO: Linum usitatissimum oil.

\section{Conclusion}

The present study showed that oral administration of Linum usitatissimum has potential antidiabetic, antihyperlipidemic and antioxidant effect in STZ induced diabetic rats. The potent antioxidant activity may be responsible for the antihyperglycemic and antihyperlipidemic effects. Thus the investigation reveals that $L$. usitatissimum can be used as a natural oral agent with antihyperglycemic, antihyperlipidemic and antioxidant effects.

\section{ACKNOWLEDGEMENT}

The authors are highly grateful to the University Grants Commission, Delhi (India) for providing research fellowship during research work.

\section{REFERENCES}

Betteridge J (1997). Lipid disorders in diabetes mellitus, in: J.C. Pickup, G. Williams (Eds.), Text Book of Diabetes, Blackwell Science Publishers, London, pp. 1-35.

Bonadonna RC, Groop LC, Zych K, Shank M, DeFronzo RA (1990). Dose dependent effect of insulin on plasma free fatty acid turnover and oxidation in humans. Am. J. Physiol. 259:736-750.

Brown WV (1994). Lipoprotein disorders in diabetes mellitus. Med. Clin. North Am. 78:143-161.

Campbell PJ, Carlson MG, Hill JO, Nurjhan N (1992). Regulation of free fatty acid metabolism by insulin in humans: role of lipolysis and reesterification. Am. J. Physiol. 263:1063-1069.

Chakravarti BK, Gupta S, Gambir SS, Gode KD (1981). Pancreatic betacell regeneration in rats by $(-)$ epicatechin. The Lancet 2:759760

Chattopadhyay RR (1999). Possible mechanism of antihyperglycemic effect of Azadirachta indica leaf extract. J. Ethanopharmacol. 67:373376.

Flat SK, Day C, Bailey CJ, Flatt PR (1990). Traditional plant treatments for diabetes: studies in normal and streptozotocin diabetic mice. Diabetologia 33:462-464.

Gallagher AM, Flatt PR, Duffy G, Abdel-Wahab YHA (2003). The effects of traditional antidiabetic plants on in vitro glucose diffusion. Nutr. Res. 23(3):413-424

Gupta SS (1994). Prospects and perspectives of natural plant products in medicine. Ind. J. Pharmacol. 26:5-9.
Jaiprakash R, Rani NMA, Venkataraman BV (1993). Effect of felodipine on serum lipid profile in short term streptozotocin diabetes in rats, Indian, J. Exp. Biol. 31:283-284.

Kumar S, Kamboj J, Sharma S (2011). In vivo Anti-diabetic and Antioxidant potential of Psoralea corylifolia seeds in Streptozotocin induced type- 2 diabetic rats. J. health Sci. 57(3):1-11.

Kumar S, Sharma S, Vasudeva N (2012). GC-MS analysis and screening of antidiabetic, antioxidant and hypolipidemic potential of Cinnamomum tamala oil in streptozotocin induced diabetes mellitus in rats. Cardiovasc. Diabetol. 11:95

Kumar S, Sharma S, Vasudeva N, Ranga V (2012). In vivo antihyperglycemic and antioxidant potentials of ethanolic extract from Tecomella undulata. Diabetol. Metab. Syndrome 4:33.

Kumar S, Singh R, Sharma S, Vasudeva N (2012). Acute and chronic animal models for the evaluation of anti-diabetic agents. Cardiovasc. Diabetol. 11:9.

Lewis HS, Elvin-Lewis MPH (1977). Plants affecting man's health, in: Medical Botany, Wiley, New York, pp. 217-218.

Momin A (1987). Role of indigenous medicine in primary health care, in: Proceedings of First International Seminar on Unani Medicine, New Delhi, India, p. 54.

Nadkarni AK (1992). Indian Materia Medica, vol. 1, Popular Prakashan Ltd., Bombay,

Okhawa H, Ohishi N, Yagi K (1979). Assay for lipid peroxides in animal tissue by thiobarbituric acid reaction. Anal. Biochem. 95:351-358.

Okutan H, Ozcelik N, Yilmaz HR, Uz E (2005). Effects of phenethyl ester on lipid peroxidation and anti oxidant enzymes in diabetic rat heart. Clin. Biochem. 38:191-196.

Rubilar M, Gutiérrez C, Verdugo1 M, Shene C, Sineiro J (2010). Flaxseed as a source of functional ingredients. J. soil Sci. Plant Nutr. 10(3):373-377

Seifter S, Dayton S, Molic B, Mutwzter E (1950). The estimation of glycogen with the anthrone reagent. Arch. Biochem. 25(1):191-200.

Sheela GC, Augusti K (1992). Antidiabetic effects of S-allyl cystine sulphoxide isolated from garlic Allium sativum Linn. Indian J. Exp. Biol. 30:523-526.

Stamler I, Vaccaro O, Neaton JD, Wentworth D (1993). Diabetes, other risk factors and 12-yr cardiovascular mortality for men screened in the multiple risk factor intervention trial, Diabetes Care 15:434-444.

Tian YM, Johnson G, Ashcroft JH (1998). Sulfonylureas enhance exocytosis from pancreatic b-cells by a mechanism that does not involve direct activation of protein kinase C. Diabetes 47:1722-1726.

Tunali S, Yanardag R (2006). Effect of vanadyl sulfate on the status of lipid parameters and on stomach and spleen tissues of streptozotocin-induced diabetic rats. Pharmacol. Res. 53:271-277.

Twaij HAA, Al-Badr AA (1988). Hypoglycaemic activity of Artemisia herba alba, J. Ethnopharmacol. 24:123-126.

Velisek J, Mikulcova R, Mikova K, Woldie KS, Link J, Davídek J (1995). Chemometric investigation of mustard seed. Lebenson Wiss Technol. 28(6):620-624. 